first four species there is a close correlation between hyaluronidase content and sperm density. In the case of dogs and fowls no such correlation could be found.

2. The absence of hyaluronidase in a cryptorchid and in prepubertal rabbit testes is demonstrated. The conclusion is reached that seminal hyaluronidase originates in active seminiferous epithelium and is not secreted by the accessory glands.

3. The bearing of these results on the role of hyaluronidase in fertilization and its implication in the possibility of treatment of infertility due to oligospermia is discussed.

Acknowledgements are most gratefully made to Dr A. S. Parkes for constant advice and encouragement; to Drs S. J. Folley, E. C. Amoroso, M. Rose, P. M. F. Bishop, M. Jackson, Mrs C. Harvey, Mr D. J. G. Black and Mrs C. Wallace for providing seminal specimens from various species, and to Dr C. W. Emmens for statistical assistance.

\title{
REFERENCES
}

Brambell, F. W. R. (1925). Philos. Trans. B, 214, 113. Chain, E. \& Duthie, E. S. (1940). Brit. J. exp. Path. 21, 324. Fekete, E. \& Duran-Reynals, F. (1943). Proc. Soc. exp. Biol., N.Y., 52, 119.

Hamilton, W. J. \& Laing, J. A. (1946). J. Anat., Lond., 80, 194.

Hoffman, D. C. \& Duran-Reynals, F. (1931). J. exp. Med. $53,387$.

Humphrey, J. H. (1943). Biochem. J. 37, 177.

Joël, C. A. \& Eichenberger, E. (1945). Schweiz. med. Wschr. 27,601 .

Leonard, S. L. \& Kurzrok, R. (1945). Endocrinology, 37, 171.

Long, J. A. (1912). Univ. Calif. Publ. Zool. 9, 105.

McClean, D. (1930). J. Path. Bact. 33, 1045.

McClean, D. (1931). J. Path. Bact. 34, 459.
McClean, D. (1943). Biochem. J. 37, 169.

McClean, D. \& Hale, C. W. (1941). Biochem. J. 35, 159.

McClean, D. \& Rowlands, I. W. (1942). Nature, Lond., 150, 627.

Meyer, K., Dubos, R. \& Smythe, E. M. (1937). J. biol. Chem. 118, 71.

Pincus, G. (1930). Proc. Roy. Soc. B, 107, 132.

Pincus, G. \& Enzmann, E. V. (1932). J. exp. Biol. 9, $40 \dot{3}$.

Pincus, G. \& Enzmann, E. V. (1935). J. exp. Med. 62, 665.

Rowlands, I. W. (1944). Nature, Lond., 154, 332.

Swyer, G. I. M. (1947). Biochem. J. 41, 413.

Swyer, G. I. M. \& Emmens, C. W. (1947). Biochem. J. 41, 29.

Werthessen, N. T., Berman, S., Greenberg, B. E. \& Gargill, S. L. (1945). J. Urol. 54, 565.

Yamane, J. (1930). Cytologia, Tokio, 1, 394.

\section{The Release of Hyaluronidase from Spermatozoa}

\author{
By G. I. M. SWYER, National Institute for Medical Research, Hampstead, N.W. 3
}

(Received 11 February 1947)

The belief that seminal hyaluronidase is associated with spermatozoa rather than with the seminal plasma is suggested by the close correlation between hyaluronidase content and sperm density in several species of mammals; by the absence of hyaluronidase from azoöspermic semen; and by its presence in testes in which active spermatogenesis is taking place and its absence in inactive testes (prepubertal and cryptorchid), as shown in an accompanying paper (Swyer, 1947). The present report is concerned with some of the factors which appear to be involved in the liberation of the hyaluronidase contained in spermatozoa.

\section{EXPERIMENTAL}

Material and methods. All the experiments to be described were carried out with rabbit semen obtained by the artificial vagina technique. Hyaluronidase assays were made by the method of Swyer \& Emmens (1947), the unit of hyaluronidase activity being that described by these authors. The standard error of this method is less than $10 \%$.

\section{Extraction of hyaluronidase with water}

McClean (1931) showed that extracts of spermatozoa made with distilled water contain large amounts of the 'spreading factor' now known to be hyaluronidase. It was observed, however, that if an aqueous suspension of spermatozoa were assayed within a short time of being made up, the hyaluronidase value obtained was less than if the suspension had been allowed to stand for some hours before assaying.

The following experiment, therefore, was performed to investigate this point. Three pooled ejaculates were used; four suspensions were made by adding $0.2 \mathrm{ml}$. semen to $9 \cdot 8 \mathrm{ml}$. distilled water. A fifth portion of $0.2 \mathrm{ml}$. semen was freeze-dried in an ampoule. The five samples of semen were then subjected to the treatment shown in Table 1 and assayed for hyaluronidase. The values, expressed in units $/ \mathrm{ml}$. of semen show that a short period of freezing at $-10^{\circ}$, or a considerable period of standing at $0^{\circ}$ enabled an apparently maximal amount of 
Table 1. Effect of various treatments on extraction of hyaluronidase from aqueous suspensions of spermatozoa

\begin{tabular}{|c|c|c|c|c|c|c|c|c|}
\hline Suspension & $\ldots$ & $\ldots$ & $\ldots$ & 1 & 2 & 3 & 4 & 5 \\
\hline Treatment & ... & ... & $\ldots$ & $\begin{array}{l}\text { Assayed } \\
\text { within } \\
40 \mathrm{~min} .\end{array}$ & $\begin{array}{c}\text { Frozen for } \\
3 \mathrm{hr} \text {. at }-10^{\circ} \\
\text { before assay }\end{array}$ & $\begin{array}{l}24 \mathrm{hr} \text {. at } \\
0^{\circ} \text { before } \\
\text { assay }\end{array}$ & $\begin{array}{l}\text { Frozen for } \\
6 \text { days before } \\
\text { assay }\end{array}$ & $\begin{array}{c}\text { Freeze-dried: } \\
\text { assayed } 6 \text { days } \\
\text { later }\end{array}$ \\
\hline Hyaluronid & nits & & & $41 \cdot 5$ & $89 \cdot 5$ & $84 \cdot 5$ & $83 \cdot 5$ & 82 \\
\hline
\end{tabular}

hyaluronidase to pass into solution. It can also be seen that prolonged freezing resulted neither in increased extraction nor in significant loss of potency of the extract, while freeze-drying destroyed only a small fraction of the potency. Freeze-dried semen preparations, it may be mentioned, have been found to suffer no change of potency over periods exceeding 6 months.

In order to test whether freezing the semen suspension is sufficient to extract all the available hyaluronidase, a further suspension, made up as above, was frozen for $24 \mathrm{hr}$., thawed and centrifuged. The supernatant was removed and the deposit of sperms resuspended in $5 \mathrm{ml}$. water and immediately centrifuged for $10 \mathrm{~min}$. The supernatant was discarded and the sperms ground up with sand, shaken with $5 \mathrm{ml}$. water and filtered. The filtrate was then tested for hyaluronidase activity, but none was found, suggesting that extraction by freezing was complete.

\section{Liberation of hyaluronidase in Baker's solution}

The foregoing experiments showed that hyaluronidase was liberated from dead sperms in aqueous suspension. The question then arose whether living sperms could liberate hyaluronidase, and for this purpose, sperm suspensions in Baker's (1931) solution were studied. In the first place, it was found that when samples $(0.2 \mathrm{ml}$.) of semen were suspended in equal quantities $(9.8 \mathrm{ml}$.) of water or Baker's solution, frozen, thawed and assayed, no significant difference in the hyaluronidase values was obtained $(87.5$ and 86 units $/ \mathrm{ml}$. semen respectively). Baker's solution, therefore, does not appear to interfere with hyaluronidase assay.

In order to compare the liberation of hyaluronidase in a water suspension with that in Baker's solution suspension in which the sperms remain alive, the experiment recorded in Table 2 was performed. From four pooled ejaculates, two suspensions containing $0.2 \mathrm{ml}$. semen in $4.8 \mathrm{ml}$. water, and a third containing $0.2 \mathrm{ml}$. semen in $4.8 \mathrm{ml}$. Baker's solution were made. One of the aqueous suspensions was left at $0^{\circ}$ for $24 \mathrm{hr}$. and on assay yielded 87.5 units $/ \mathrm{ml}$. semen. The other two suspensions were treated as shown in Table 2, the spermatozoa in each instance being separated by centrifuging for $10 \mathrm{~min}$. (the times indicated in the table include this period of centrifuging).

It will be seen from Table 2 that there was no significant difference between supernatants $1 a$ and
Table 2. Hyaluronidase contents of supernatants from suspensions of spermatozoa (a) in water and (b) in Baker's solution. Supernatants removed at times shown, the sperm deposits in each case being resuspended in fresh water or Baker's solution as before, reconstituting the original volumes of suspensions

Hyaluronidase

\begin{tabular}{|c|c|c|c|}
\hline \multirow[b]{2}{*}{ Supernatant } & \multirow{2}{*}{$\begin{array}{l}\text { Time of } \\
\text { removal } \\
\text { from } \\
\text { suspension } \\
\text { (min.) }\end{array}$} & \multicolumn{2}{|c|}{ (units/ml. semen) } \\
\hline & & $\begin{array}{l}\text { Aqueous } \\
\qquad(a)\end{array}$ & $\begin{array}{l}\text { Baker's } \\
\text { solution } \\
\text { (b) }\end{array}$ \\
\hline $\begin{array}{l}1 \\
2 \\
3\end{array}$ & $\begin{array}{r}10 \\
160 \\
120\end{array}$ & $\begin{array}{l}21 \\
18 \cdot 5 \\
11\end{array}$ & $\begin{array}{l}21 \cdot 5 \\
9 \cdot 25 \\
6\end{array}$ \\
\hline Total & 290 & $50 \cdot 5$ & $36 \cdot 75$ \\
\hline
\end{tabular}

$1 b$, from which it was thought that the value obtained represented, for the most part at any rate, that of the hyaluronidase actually in solution in the plasma. (A subsequent experiment, described below, would suggest that these values also include some hyaluronidase liberated from the spermatozoa.) The hyaluronidase contents of supernatants $2 a, 2 b, 3 a$ and $3 b$ show that, under similar circumstances, the enzyme is liberated in significantly larger amounts in aqueous than in Baker's solution suspensions. The results of the whole experiment also confirm the belief that the major part (at least $\frac{3}{4}$ ) of the hyaluronidase of semen as ejaculated is associated with the sperm fraction, while the remainder must be regarded as having passed from the spermatozoa into solution in the plasma.

To see whether the results obtained in the above experiment gave an indication of the rate of release of hyaluronidase, a suspension of spermatozoa was made by adding $0.2 \mathrm{ml}$. semen (not the same as that used in the previous experiment) to $19.8 \mathrm{ml}$. Baker's solution from which successive portions were removed at intervals and centrifuged for $10 \mathrm{~min}$. The supernatants were separated and assayed. The supernatant of the first portion, removed after 5 min., yielded 18.5 units of hyaluronidase/ml. semen; that of the second, removed after 25 min., 17.5 units; that of the third, removed after 50 min., 18 units; and that of the fourth, removed after $80 \mathrm{~min}$., 19 units. There is no significant difference in these values, whence it may be concluded that the amount of hyaluronidase which passes into solution in a suspension of live spermatozoa in Baker's solution is the same whether the sper. 
matozoa remain in contact with the suspending medium for $15 \mathrm{~min}$. or for $90 \mathrm{~min}$. The results of the previous experiment, therefore, do not indicate the rate of liberation of hyaluronidase.

\section{Absence of hyaluronidase production by spermatozoa}

To investigate whether live spermatozoa produce hyaluronidase, or whether they merely liberate the preformed enzyme, three pooled ejaculates were used. Successive $\mathbf{0 . 2} \mathrm{ml}$. portions were suspended in $4.8 \mathrm{ml}$. water and in two similar volumes of Baker's solution. The aqueous suspension was immediately frozen. One of the Baker's solution suspensions was then heated to $56^{\circ}$ until all the sperms were killed (30 min.) after which it and the other Baker's solution suspension were left for $24 \mathrm{hr}$. at room temperature, by which time the sperms in the unheated suspension were sluggishly motile. Both suspensions were then frozen for $24 \mathrm{hr}$. Hyaluronidase assays gave values of 66,60 and 56 units $/ \mathrm{ml}$. semen for the aqueous, unheated and heated Baker's solution suspensions respectively. Over the period of $24 \mathrm{hr}$., therefore, no detectable production of hyaluronidase occurred. The lower value of the heated suspension may be ascribed to some destruction of enzyme by the heating.

Effect of concentration of spermatozoa on liberation of hyaluronidase from spermatozoa suspended in Baker's solution

Portions $(0.1 \mathrm{ml}$.) of three pooled ejaculates were diluted with Baker's solution to make suspensions of 4, 8 and $16 \mathrm{ml}$. respectively. After $1 \mathrm{hr}$. the suspensions were centrifuged, and the supernatants removed and assayed. Two other similar experiments were performed, the volumes of suspension in these being 3, 6, 12 and $24 \mathrm{ml}$. respectively. The results are shown in Fig. 1. When the quantities of hyaluronidase liberated are plotted against the logarithm of the volume of suspension, it can be seen that over the range of volumes used there is a close approximation to a straight line relationship. This is an indication that the liberation of hyaluronidase from live spermatozoa may follow fairly simple physico-chemical laws.

It now became of interest to see. whether the presence of hyaluronidase in the suspending medium influenced the extent to which the enzyme was liberated from spermatozoa placed in such a medium. Accordingly, a solution of hyaluronidase in Baker's fluid was prepared by adding $1 \mathrm{ml}$. semen to $24 \mathrm{ml}$. Baker's solution, freezing the suspension to liberate the enzyme followed by thawing and centrifuging. To $19.8 \mathrm{ml}$. of the supernatant $0.2 \mathrm{ml}$. of semen was added, while an equal quantity of semen was suspended in a further $19.8 \mathrm{ml}$. of Baker's solution. After $50 \mathrm{~min}$. both suspensions were centrifuged for
$10 \mathrm{~min}$, the supernatants were discarded and to each deposit $10 \mathrm{ml}$. of water were added, the sperms being stirred up and the suspension then frozen to liberate the remaining hyaluronidase. The suspensions were then assayed the results being $\mathbf{3 0 . 5}$ and 23 units $/ \mathrm{ml}$. semen respectively, thus indicating that $7 \cdot 5$ units $/ \mathrm{ml}$. of hyaluronidase were retained by the spermatozoa which had been suspended in the hyaluronidase-containing Baker's solution.

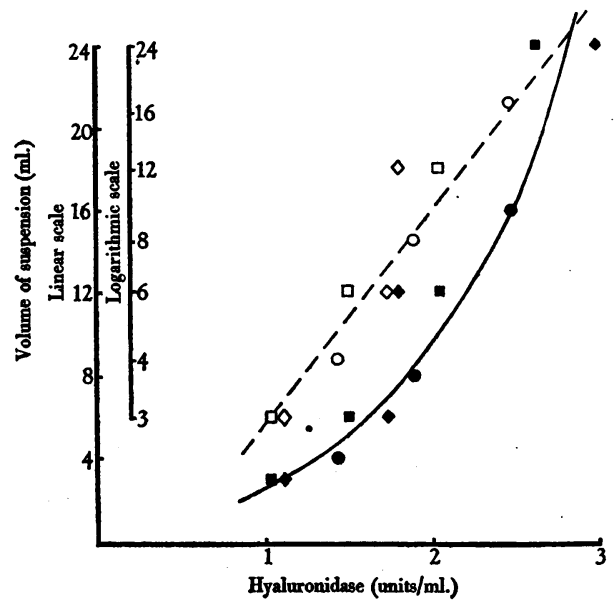

Fig. 1. Relationship between quantity of hyaluronidase liberated from $0.2 \mathrm{ml}$. semen suspended in Baker's

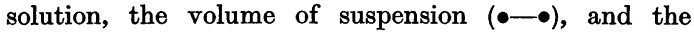
logarithm of the volume of suspension (o-.- o). The different symbols refer to the three experiments. (The straight line is not a fitted regression line.)

\section{Effect of hyaluronate and heparin on liberation of hyaluronidase from spermatozoa}

On the assumption that the cement substance of the cumulus surrounding freshly ovulated mammalian eggs is composed of hyaluronic acid (McClean \& Rowlands, 1942) and that a loose combination between enzyme and substrate might lower the effective concentration of the latter in the vicinity of the egg, it seemed possible that the presence of hyaluronate might accelerate the liberation of hyaluronidase from spermatozoa. To investigate this point, and at the same time to investigate what effect heparin, a hyaluronidase inhibitor (McClean, 1942; Rogers, 1946), might have on hyaluronidase liberation, the following experiment was carried out.

Two pooled ejaculates were used and three suspensions were made by adding successive portions of $\mathbf{0 . 3} \mathbf{~ m l}$. semen to $\mathbf{9 . 7} \mathrm{ml}$. amounts of Baker's fluid. One of the suspensions was made to contain $10 \mathrm{mg}$. heparin (1000 Toronto units) and another $0.1 \mathrm{~g}$. potassium hyaluronate. The activity of the sperms was found to be equal in all three suspensions at the start of the experiment. The suspensions were then 
placed in a $37^{\circ}$ incubator for $1 \frac{1}{2} \mathrm{hr}$., at the end of which time sperm activity was still approximately equal, although there was a good deal of head agglutination in the suspension containing hyaluronate. The suspensions were centrifuged for 10 min., when the deposit in the plain Baker's solution was resuspended in its own supernatant, while the other two supernatants were discarded, physiological saline being added to the original level, and the deposits stirred up. The suspensions were frozen to liberate the hyaluronidase remaining in the sperms. Assay of the plain Baker's solution suspension yielded 43.5 units of hyaluronidase $/ \mathrm{ml}$. semen; of the heparin-containing suspension 29.5 units/ml.; of the hyaluronate-containing suspension, 33 units $/ \mathrm{ml}$. These latter two values are not significantly different, and indicate that between onequarter and one-third of the total hyaluronidase has passed into solution. Since this is about the expected amount which would have entered solution in a plain Baker's solution suspension it must be concluded that the presence neither of hyaluronate nor of heparin has any appreciable effect on the liberation of hyaluronidase from spermatozoa.

\section{DISCUSSION}

The experiments described above indicate the conditions under which apparently complete extraction of seminal hyaluronidase can be achieved-namely, freezing for a short period or suspension in water for some $24 \mathrm{hr}$. at $0^{\circ}$. They demonstrate, moreover, the possibility of extracting hyaluronidase from washed spermatozoa and, by showing that at least threequarters of the total hyaluronidase content of semen as ejaculated is associated with the spermatozoa, confirm the supposition that hyaluronidase production is a function of the seminiferous epithelium and not of the accessory glands. From the point of view of the function of seminal hyaluronidase, if this is conveyed by the spermatozoa to the vicinity of the freshly ovulated egg, there to effect disintegration of the cumulus (McClean \& Rowlands, 1942), the question naturally arises as to the nature of the mechanism which ensures liberation of the enzyme at its point of action. The evidence presented in this paper enables certain conclusions to be drawn in this connexion. In the first place, the presence of hyaluronic acid, the substrate on which the enzyme acts, appears to have no effect in determining the liberation of the enzyme from spermatozoa, and it may be presumed that the presence of a cumulus is similarly without effect. Experiments designed to test the effect of saline extracts of Fallopian tube on the rate of disintegration of rabbit cumuli in sperm suspensions revealed a similar absence of effect (unpublished observation). No specific mechanism, therefore, which would ensure selective liberation of the enzyme in the Fallopian tube, appears to exist.
The most significant light on this subject, however, would appear to be that afforded by observations on the effect of the concentration of sperm suspensions in Baker's solution on the quantity of hyaluronidase liberated. These indicate that as the sperms ascend the female reproductive tract, moving continually into a fresh medium, they undergo a progressive loss of hyaluronidase, the latter passing into solution in the fluid within the lumen of the tract. This being so, the concentration of hyaluronidase established in the Fallopian tube is actually lower than in other parts of the female reproductive tract.

The mode of release of hyaluronidase from spermatozoa has further implications. In the first place, it suggested that the presence of hyaluronidase in solution in the suspending medium would reduce the extent to which the enzyme was liberated by spermatozoa in such a suspension. This was, in fact, found to be the case and it throws an interesting light on the experiments of Rowlands (1944) on the capacity of hyaluronidase to increase the fertilizing power of dilute sperm suspensions in rabbits. In these experiments the sperm suspensions were made by diluting with Baker's solution for the controls, or with a hyaluronidase-containing sperm-free filtrate of a concentrated suspension of spermatozoa in Baker's solution, heated to $56^{\circ}$ for a length of time just sufficient to kill the spermatozoa. The results showed that the treated inseminate required on the average one-sixth the number of spermatozoa as did the control inseminates, in order to fertilize a particular percentage of ova. The question naturally arose as to how the added hyaluronidase ascended the reproductive tract so as to assist fertilization. The unaided ascent of the enzyme was a possibility, but observations (unpublished) by the author on the passage through the reproductive tract of hyaluronidase introduced in solution into the vagina of rabbits suggest that though occasionally this may occur to a significant extent, in general it is not possible to demonstrate hyaluronidase activity in tubal washings of rabbits thus treated. The most probable explanation, therefore, is that the sperms in the treated inseminates retained a significantly greater proportion of their hyaluronidase which, accordingly, was available for action on the cumuli within the Fallopian tubes.

Recent observations by Chang $(1946 a, b)$ on the minimal numbers of sperms required to fertilize rabbit ova have revealed the existence of a variety of factors influencing such numbers. Thus, the percentage of ova fertilized by a given small number of sperms depends upon the number of ova ovulated and the maturity of the animal. More important from the point of view of present considerations is the finding that the dilution of an inseminate containing a small number of sperms affects its fertilizing capacity. Thus, the percentages of fertilized 
ova were 17-42, 0-28 and 0-6\% when inseminates containing 30,000-44,000 sperms had volumes of $0.1,0.4$ and $1.0 \mathrm{ml}$. respectively. In seeking an explanation for this effect, Chang (1946b) suggested that in the more dilute suspensions fewer sperms were able to enter the cervix uteri and so reach the Fallopian tubes. Though this may well be true it is probable that at least two other factors may apply. In the first place, the evidence presented in this paper shows that the sperms in the more dilute suspensions would contain less hyaluronidase, while in the second, it has been observed that the survival time of sperms in dilute suspensions in Baker's solution is greatly reduced. For example, whereas a suspension containing 10-20 millions $/ \mathrm{ml}$. may survive for $36 \mathrm{hr}$. or more at room temperature, the survival time of a suspension containing 1 million $/ \mathrm{ml}$. may be less than $1 \mathrm{hr}$. No explanation for this phenomenon has yet been found, but it has prevented the carrying out of an experiment which the previous results have obviously suggested, namely, the possibility of sperms whose hyaluronidase content has been depleted being made to reabsorb the enzyme on being suspended in a medium rich in the latter.

\section{SUMMARY}

1. Investigation of some of the factors concerned in the liberation of hyaluronidase from rabbit sper- matozoa has shown that freezing for a short time or standing in aqueous suspension at $0^{\circ}$ for $24 \mathrm{hr}$. or longer allows apparently maximal extraction of the enzyme. Freeze-drying may cause an insignificant loss of potency but the product remains stable for long periods.

2. At least three quarters of the total hyaluronidase content of semen is associated with the spermatozoa, the remainder being in solution in the plasma. In suspensions of live sperms in Baker's solution, the amount of hyaluronidase in solution is roughly proportional to the logarithm of the volume of suspension for a constant number of sperms. The presence of hyaluronidase in solution in the suspending medium reduces the amount of enzyme liberated by the sperms.

3. Spermatozoa do not appear actively to produce hyaluronidase; they merely liberate the preformed enzyme.

4. It is suggested that the mechanism which accounts for the relationship between volume of suspension and hyaluronidase liberated is sufficient to explain the release of enzyme in the Fallopian tubes necessary to bring about disintegration of the cumulus surrounding freshly ovulated ova.

I wish to express my warmest thanks to Drs A. S. Parkes and C. W. Emmens for their advice and criticism, and to Mrs C. Harvey for some valuable suggestions.

\title{
REFERENCES
}

Baker, J. R. (1931). Quart. J. exp. Physiol. 21, 139.

Chang, M. C. (1946a). Federat. Proc. 5, 16.

Chang, M. C. (1946b). Science, 104, 361.

McClean, D. (1931). J. Path. Bact. 34, 459.

McClean, D. (1942). J. Path. Bact. 54, 284.

McClean, D. \& Rowlands, I. W. (1942). Nature, Lond., 150, 627.
Rogers, H. J. (1946). Biochem. J. 40, 583.

Rowlands, I. W. (1944). Nature, Lond., 154, 332.

Swyer, G. I. M. (1947). Biochem. J. 41, 409.

Swyer, G. I. M. \& Emmens, C. W. (1947). Biochem. J. 41, $29^{\circ}$.

\section{The Metabolic Conversion of Naphthalene to 1:2-Dihydronaphthalene-1:2-diol}

\author{
By L. YOUNG,* Department of Biochemistry, University of Toronto
}

(Received 23 December 1946)

Studies of the metabolism of naphthalene (Bourne \& Young, 1933 $a, b, 1934$; Ing, Bourne \& Young, 1934) and anthracene (Boyland \& Levi, 1935, 1936a, b) have revealed certain similarities in the chemical changes which these hydrocarbons undergo in the animal body. Both are converted to mercapturic acids and both give rise to derivatives which yield the parent hydrocarbons when decomposed by acid. The

* Now at University College, London. purpose of the present work was to determine whether the administration of naphthalene to the rat is followed by the excretion of a derivative analogous to 1:2-dihydroxy-1:2-dihydroanthracene, a compound which was isolated by Boyland \& Levi (1935) from the urine of rats and rabbits to whose diet anthracene had been added.

Naphthalene, in the form of a solution in corn oil, was injected subcutaneously into rats. From the 